\title{
Robust TLR4-induced gene expression patterns are not an accurate indicator of human immunity
}

\author{
Kelly L Brown ${ }^{1,2,4^{*}}$, Reza Falsafi ${ }^{1}$, Winnie Kum ${ }^{1}$, Pamela Hamill1, Jennifer L Gardy ${ }^{1}$, Donald J Davidson ${ }^{2,3}$, \\ Stuart Turvey ${ }^{2}$, Brett B Finlay ${ }^{1}$, David P Speert ${ }^{2}$, Robert EW Hancock ${ }^{1}$
}

\begin{abstract}
Background: Activation of Toll-like receptors (TLRs) is widely accepted as an essential event for defence against infection. Many TLRs utilize a common signalling pathway that relies on activation of the kinase IRAK4 and the transcription factor $\mathrm{NF} \kappa \mathrm{B}$ for the rapid expression of immunity genes.

Methods: 21 K DNA microarray technology was used to evaluate LPS-induced (TLR4) gene responses in blood monocytes from a child with an IRAK4-deficiency. In vitro responsiveness to LPS was confirmed by real-time PCR and ELISA and compared to the clinical predisposition of the child and IRAK4-deficient mice to Gram negative infection.

Results: We demonstrated that the vast majority of LPS-responsive genes in IRAK4-deficient monocytes were greatly suppressed, an observation that is consistent with the described role for IRAK4 as an essential component of TLR4 signalling. The severely impaired response to LPS, however, is inconsistent with a remarkably low incidence of Gram negative infections observed in this child and other children with IRAK4-deficiency. This unpredicted clinical phenotype was validated by demonstrating that IRAK4-deficient mice had a similar resistance to infection with Gram negative S. typhimurium as wildtype mice. A number of immunity genes, such as chemokines, were expressed at normal levels in human IRAK4-deficient monocytes, indicating that particular IRAK4-independent elements within the repertoire of TLR4-induced responses are expressed.
\end{abstract}

Conclusions: Sufficient defence to Gram negative immunity does not require IRAK4 or a robust, 'classic' inflammatory and immune response.

\section{Background}

Toll-like receptor-4 (TLR4) is a prominent member of the TLR family of host receptors that recognize microbial components in the intra- and extra-cellular environment [1,2]. Lipopolysaccharide (LPS, endotoxin) is a major component of the cell wall of Gram negative bacteria, a potent TLR4 agonist and the driving force behind sepsis. TLR4 engagement by LPS results in the activation of the transcription factor $\mathrm{NF} \kappa \mathrm{B}$ via signal transduction cascades that are propagated either through, or independent of, the adaptor molecule MyD88 [2-4]. Organisms amenable to genetic manipulation have been used to evaluate the importance of TLR4 and various downstream signalling molecules for the

\footnotetext{
* Correspondence: kelly.brown@rheuma.gu.se

${ }^{1}$ Centre for Microbial Diseases and Immunity Research, Department of Microbiology and Immunology, University of British Columbia, Vancouver,
} British Columbia, V6T 1Z3, Canada
(LPS-)induced expression of immunity genes (most commonly cytokines including chemokines) and defence against various pathogens [5,6], e.g., MyD88-knockout mice fail to elevate serum cytokines when administered a high dose of LPS and are susceptible to infection by $S$. aureus [7], P. aeruginosa [8], M. tuberculosis [9], M. avium [10] and L. monocytogenes [11]. Such studies have established that the MyD88-dependent pathway, via sequential activation of IRAK4, IRAK1, TRAF6, IKK and $\mathrm{NF} \kappa \mathrm{B}$, drives a cellular response to TLR agonists that is responsible for the robust expression of earlyresponse, NF $\kappa \mathrm{B}$-regulated immunity genes. It has been often assumed that this robust transcriptional response, involving the substantial induction of a large number of genes $(>1000)$ is essential for normal immunological function(s) and, in turn, host defences. Moreover, the reduced expression, either in vitro or in vivo, of just a subset of TLR-responsive genes, such as the classic pro-
C Biomed Central

C 2010 Brown et al; licensee BioMed Central Ltd. This is an Open Access article distributed under the terms of the Creative Commons Attribution License (http://creativecommons.org/licenses/by/2.0), which permits unrestricted use, distribution, and reproduction in any medium, provided the original work is properly cited. 
inflammatory cytokines (TNF- $\alpha$, IL-6), chemokines (IL8 , Gro- $\alpha /$ CXCL1) and antibacterials (antimicrobial peptides, reactive oxygen/nitrogen species) is often accepted as sufficient evidence to predict a defect in host defence against infectious agents.

Since 2003, eighteen individuals, primarily children, have been identified with a mutation in the gene that encodes IL-1R-associated kinase 4 (IRAK4) that lies immediately downstream of MyD88 in the TLR signalling cascade (reviewed in [12]). We previously reported an IRAK4-deficiency in a 4-year old child due to a homozygous single base substitution $(\mathrm{C} 887 \mathrm{~T})$ in exon 8 of the IRAK4 gene that introduced a premature stop codon (Q293X) [13,14]; an identical mutation occurs in the majority of cases of IRAK4 immunodeficiency. PBMC from children with IRAK4-deficiency consistently show impaired in vitro responsiveness, as measured by the production of pro-inflammatory cytokines, to selected TLR agonists [12-14]. Given the pivotal position of IRAK4 in the TLR pathway and the failed responsiveness of IRAK4-deficient (human and mouse) cells to both Gram positive (LTA, PGN) and Gram negative (LPS) TLR agonists, it seemed logical that a defect in IRAK4 would render patients susceptible to a broad range of both Gram positive and Gram negative bacterial pathogens. In contrast, children with an IRAK4-deficiency have a remarkably mild immunodeficiency with enhanced susceptibility to infection by only a narrow range of Gram positive bacteria, particularly S. aureus and S. pneumoniae [12-18]. IRAK4 knockout mice are also more susceptible to infections by (Gram positive) $S$. aureus than wild-type mice [19]. We were intrigued by the relatively small number of documented cases of Gram negative infections in IRAK4-deficient children $[20,21]$ in light of a consistently poor cellular responses to LPS. It should be noted that these children are prescribed a regimen of antibiotics that are effective only against Gram positive bacteria, thus prophylaxis can not explain their apparent immunity to Gram negative infections. IRAK4 knockout mice and IRAK4-kinase-dead knock-in mice also fail, in vitro and in vivo, to produce inflammatory cytokines in response to LPS and are protected against LPS-induced sepsis in vivo [19,22-24]. There is, however, a resounding lack of experimental evidence that IRAK4-deficiency (in humans or mice) actually compromises host defences to Gram negative infection.

Herein we provide the first evidence that IRAK4 knockout mice are not overwhelmed by challenge with the Gram negative bacterium S. typhimurium. These results substantiated our hypothesis that the underwhelming number of documented Gram negative bacterial infections in IRAK-deficient children is likely attributable to sufficient host defence. The widely accepted notion that the absence of IRAK4 should compromise immunity to Gram negative pathogens was based primarily upon results demonstrating the compromised expression of a small number of classic LPSresponsive, pro-inflammatory markers (primarily cytokines) as well as the assumption that high expression of these genes in particular was required for immunity. Here we evaluated the impact of IRAK4-deficiency on a global scale using $21 \mathrm{~K}$ microarray technology to analyze total gene expression in LPS-activated monocytes from an IRAK4-deficient patient. In accordance with previous reports, and counter-intuitive to a resistance to Gram negative infection, there was a profound failure of IRAK4-deficient monocytes to produce, in response to LPS, substantial levels of classical immunity genes (cytokines, chemokines, NF $\kappa \mathrm{B}$ subunits). Upon closer examination, however, it was discovered that the expression of these genes, while low, was seldom abolished. Moreover, approximately $20 \%$ of LPS-responsive genes, including certain chemokines, transcription factors and regulators of translation, were expressed at similar levels in control and IRAK4-deficient cells. We conclude that IRAK4 is indeed essential for LPS-induced signal transduction via the MyD88-dependent pathway that is responsible for rapid and vigorous transcription of classical $\mathrm{NF} \kappa \mathrm{B}$-regulated immunity genes, but that neither IRAK4 nor a robust transcriptional response (typical of cells exposed to LPS) are required for immunity to Gram negative infections.

\section{Methods \\ PBMC isolation and stimulation}

PBMC from healthy volunteers and the patient were prepared as previously described [25], in accordance with UBC Clinical Research Ethics Board protocol C040193. Due to the rarity of this syndrome only a single patient was available to us; however previous studies have demonstrated similar phenotypic responses for most IRAK4 deficient patients including this one [13-18]. PBMC $\left(2-3 \times 10^{7}\right.$ cells at $5 \times 10^{6}$ cells $\left./ \mathrm{ml}\right)$ were stimulated for $4 \mathrm{hr}$ at $37^{\circ} \mathrm{C} 5 \% \mathrm{CO}_{2}$ with $100 \mathrm{ng} / \mathrm{ml}$ Escherichia coli 0111:B4 LPS (Invivogen). Based on previous studies, LPS-induced gene transcription in monocytes peaked (with respect to the number of genes and the magnitude of gene expression) after $4 \mathrm{hr}$ of stimulation, at which point a substantial level of inflammatory cytokines could also be detected in the tissue culture supernatant [25]. We previously reported comparable cytokine responses in PBMC isolated from adults and children following in vitro stimulation with TLR agonists [26]; thus for ethical reasons we used adult PBMC as controls in these experiments. All reagents were tested for the absence of endotoxin and reconstituted in endotoxin-free water. 


\section{Detection of cytokines and chemokines}

Following culture of PBMC, the tissue culture supernatants were centrifuged and stored at $-80^{\circ} \mathrm{C}$ and/or measured for cytokines using a cytokine 5-Plex kit (Biosource International Inc) and Luminex $100^{\text {tm }}$ StarStation software (Applied Cytometry Systems) as described [25]. CCL22 (MDC) secretion in tissue culture supernatants was detected with a capture ELISA (R\&D Systems).

\section{Positive selection of $\mathrm{CD}_{14}^{+}$monocytes and DNA microarrays}

Following culture of PBMC, monocytes were positively selected using anti-CD14 conjugated magnetic beads (M450; Dynal; Invitrogen) as described [27,28]. RNA was isolated from monocytes with RNeasy Mini kit and analyzed using an Agilent 2100 Bioanalyzer (Agilent Technologies) as described [25]. Equal quantities of RNA from each of five healthy individuals were pooled per experimental condition to generate a reference sample of the average $(n=5)$ expression of genes in control monocytes. The profile of LPS-responsive gene expression in the control pool was consistent with what has been observed by us in monocytes from individual subjects [29]. Microarray analyses were performed on 21,000 gene arrays as previously described [29], analyzed by ArrayPipe software, version 1.6 [30], and the data deposited into ArrayExpress under accession number EFPMI-7. Differentially expressed genes were overlayed on known signal transduction pathways using Cytoscape, an open-source bioinformatics visualization software [31]. The Gene Ontology Tree Machine software [32] was used to identify gene ontology (GO) categories and biological processes with a significantly enriched (ratio $>1.0$ and $\mathrm{p}<0.01$ ) number of differentially expressed genes (indicative of dysregulation) in the patient's monocytes.

\section{Quantitative real-time PCR (qPCR)}

Differential gene expression was validated using the SuperScript $^{\mathrm{m}}$ III Platinum ${ }^{\circ}$ Two-Step qRT-PCR Kit with $\mathrm{SYBR}^{\circ}$ Green (Invitrogen) [25], using $10 \mathrm{ng}$ of total RNA as the starting material. Reported fold changes in gene expression were normalized to GAPDH in each sample and were relative to the expression of the gene in resting control monocytes. The result of qPCR analyses of more than twenty, TLR-inducible, $\mathrm{NF} \kappa \mathrm{B}$-regulated genes was in agreement with the microarray gene expression data $84 \%$ of the time; a correlation indicative of a reliable microarray data set with a relatively low incidence of false results.

\section{Bacterial culture and infection of mice}

IRAK $4^{-/-}$mice on the C57BL/6 background [19] were obtained from the Canadian Network for Vaccines and
Immunotherapeutics of Cancer and Chronic Viral Diseases (CanVac). Sex- and age-matched control C57BL/6 mice were purchased from Jackson Laboratories (Bar Harbor, Maine). Animals were used at 8-10 weeks of age. Studies were performed under pathogen-free conditions according to the standard animal care guidelines and protocols of the UBC Animal Care Committee and Canadian Council on Use of Laboratory Animals. Salmonella serovar Typhimurium wild-type strain SL1344 [33] was grown with overnight shaking $(220 \mathrm{rpm})$ in 3 $\mathrm{ml}$ Luria-Bertani (LB) broth with $50 \mu \mathrm{g} / \mathrm{ml}$ streptomycin at $37^{\circ} \mathrm{C}$ for $18 \mathrm{hr}$. Groups of eight mice were infected by oral gavage with approximately $1 \times 10^{7} \mathrm{CFU}$ in $100 \mu \mathrm{l}$ of sterile PBS. Infected mice were monitored twice daily. Mice that showed extreme distress or became moribund were euthanized and survival of the animals was recorded.

\section{Results}

IRAK4-deficient mice survive infection by the Gram negative pathogen Salmonella typhimurium

To validate the unusually low occurrence of Gram-negative infections in IRAK4-deficient children, IRAK4-deficient mice were challenged with the Gram negative bacterium, S. typhimurium. Results shown in Figure 1 demonstrated no significant difference in survival rates between IRAK4-deficient mice and wild type mice following challenge with S. typhimurium. Thus, the absence of IRAK4 does not render animals defenceless against a Gram negative bacterial challenge. These data together with that of Suzuki et al demonstrated that IRAK4 knockout mice are highly susceptible to Gram positive [19] but not necessarily Gram negative bacterial infections (Figure 1), an infection profile that emulates that of children with an IRAK4 deficiency. Thus these data strengthen our hypothesis that immunity, as opposed to prophylaxis or a lack of exposure to Gram negative bacteria, is responsible for the underwhelming number of documented Gram negative infections in children with IRAK4-deficiency.

\section{Gene expression was generally severely compromised in} IRAK4-deficient monocytes stimulated with LPS

The long-standing assumption that any deficiency in the major TLR to NF $\kappa \mathrm{B}$ pathway (such as an IRAK4-deficiency) would compromise immunity to Gram negative bacteria [34-36] was based on a substantial amount of published data demonstrating compromised expression in vitro of a limited set of LPS-induced, early-response, $\mathrm{NF} \kappa \mathrm{B}$-regulated, pro-inflammatory markers in cells deficient for various components of the TLR to NF $\kappa \mathrm{B}$ pathway (including IRAK4). A functional genomics approach was utilized here to view the broader impact of an IRAK4 deficiency on LPS-induced gene expression. 


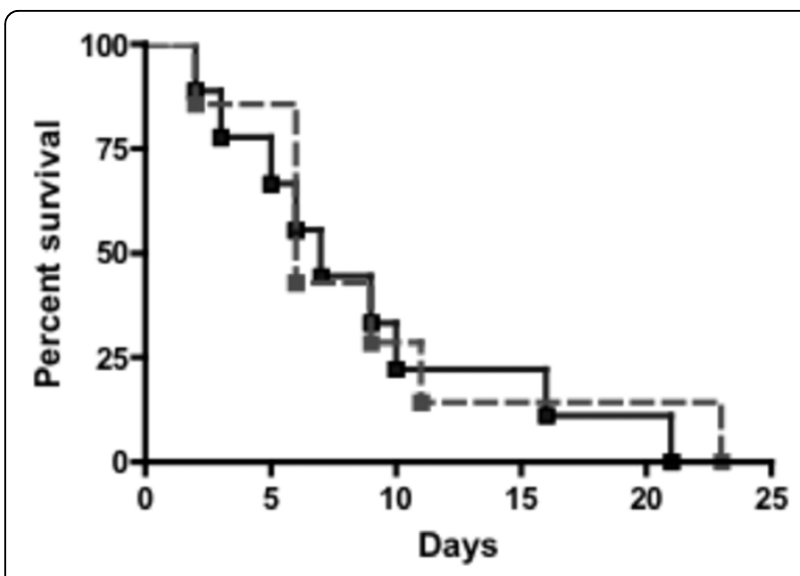

Figure 1 IRAK4-deficient mice maintain defence against Gram negative bacteria. IRAK4 ${ }^{-1}$ (dotted line) and age- and sexmatched C57BL wild type (solid line) mice were infected with $S$. typhimurium SL1344 and monitored for survival ( $y$-axis) over time ( $x$ axis). The result is representative of two independent experiments where lack of statistical significance $(p=0.69$ and $p=0.13)$ for differential survival between two groups of eight infected mice was determined by the chi-square test.

Blood monocytes were obtained from an IRAK4-deficient child and subsequently stimulated in vitro in two independent experiments, two months apart. With human $21 \mathrm{~K}$ oligo-based DNA microarray technology, the expression of genes in IRAK4-deficient monocytes from each sampling was evaluated, in triplicate, relative to gene expression in monocytes from five healthy individuals. Previous studies that employed a similar methodology $[28,29]$ served as a reference to confirm normal
LPS-responsive gene expression in the healthy, control pool of monocytes.

The expression of more than 500 genes in IRAK4-deficient cells stimulated with LPS was significantly different compared to that in control cells (567 genes, differential fold change \pm 1.5 , Student's t-test $p$-value $\leq 0.05$, results deposited in ArrayExpress, accession number E-FPMI-7). An overlay of the gene expression data on a protein map of the TLR-to-NF $\kappa \mathrm{B}$ signal transduction pathway illustrated that the majority of differentially expressed genes associated with this pathway were i) suppressed relative to gene expression in control monocytes and ii) tended to congregate downstream of the $\mathrm{I} \kappa \mathrm{B}-\mathrm{NF} \kappa \mathrm{B}$ complex (Figure 2). Gene ontology (GO) analysis [32] of the differentially expressed genes predicted that $56 \mathrm{GO}$ categories were perturbed in IRAK4-deficient patients; these constituted 5 major biological processes $(\mathrm{p}<0.01)$ namely 'immune response', 'response to biotic stimulus', 'response to stress', 'cell adhesion' and 'negative regulation of cellular processes' (data not shown).

Thus, the microarray analysis of monocytes from an IRAK4-deficient child revealed a substantial disturbance in LPS-induced gene expression, in particular in genes regulated by the TLR-to-NF $\kappa \mathrm{B}$ pathway and associated with biological processes related to immunity and cellular responsiveness to stimuli. This global analysis of gene expression in IRAK4-deficient monocytes was in accordance with previously published results that analyzed small subsets of inflammatory genes/proteins and confirmed the previously ascribed role of IRAK4 in mediating signalling from TLR4 to genes downstream of $\mathrm{NF} \kappa \mathrm{B}$.
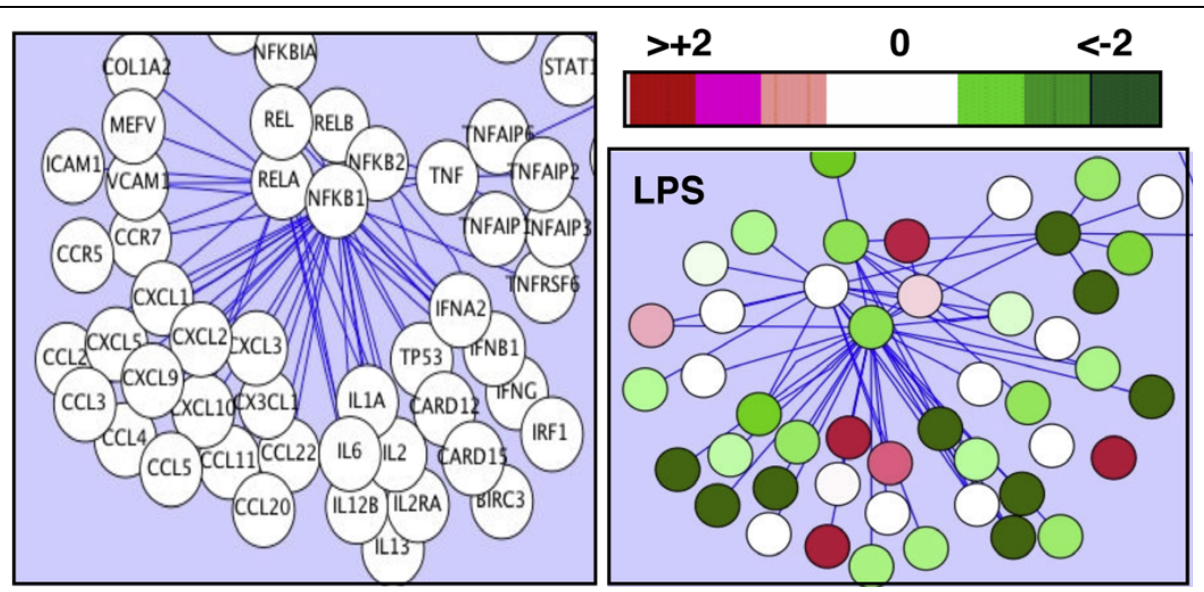

Figure 2 Differentially expressed genes in LPS-stimulated IRAK4-deficient monocytes downstream of NF $\kappa \mathbf{B}$. Using the open-source bioinformatics visualization software Cytoscape [31] gene expression in LPS-stimulated, IRAK4-deficient monocytes was overlayed on the TLR4 signal transduction pathway downstream of $\mathrm{NF} \kappa \mathrm{B}$. Gene names are given in the left panel and gene expression in the right panel. The relative expression of the gene in IRAK4-deficient monocytes is depicted by the colour of the nodes on the protein map; green nodes indicate lower expression and red nodes indicate higher expression in IRAK4-deficient monocytes relative to that in a control pool of monocytes. 
Expression of NF $\kappa \mathrm{B}$-regulated, pro-inflammatory genes was compromised to varying degrees in IRAK4-deficient monocytes

Cytokines, chemokines and certain antimicrobial peptides are TLR-sensitive, early response genes of the innate immune system that are commonly used to predict host defence and infectious disease risk. A subset of these TLR-to-NF $\kappa$ B-regulated immunity genes revealed in the microarray analyses were selected for further investigation. Genes were selected if they fit one or more of the following criteria (i) the gene was regulated by cellular activation with LPS (ii) the gene was a classic pro-inflammatory mediator, for e.g., a cytokine (TNF- $\alpha$, IL-6), chemokine (IL-8, Gro- $\alpha /$ CXCL1) or antibacterial (DEFB1) (iii) in previously published work, alteration of the expression of the gene or protein product, either in vitro or in vivo, was predicted to influence host defence, or (iv) the gene served as an internal control (for e.g., induction of $\mathrm{NF} \kappa \mathrm{B}$ subunits). Real-time quantitative PCR (qPCR) and ELISA were used to confirm the microarray results for relative gene expression between control and IRAK4-deficient monocytes, and to establish the absolute expression of mRNA and protein prior to and following stimulation with LPS.

The expression of classic pro-inflammatory cytokines and chemokines including $T N F-\alpha, I L-6, I L-12 \beta, I L-8$, Gro- $\alpha / C X C L 1, M C P-2 / C C L 8$ and MIP-3 $\alpha / C C L 20$ was compromised in LPS-stimulated IRAK4-deficient monocytes compared to LPS-stimulated control monocytes (Figure 3 and Table 1). While the expression of these genes was unanimously compromised, the degree of suppression varied considerably, from 5- to 100- fold reduction in expression (Figure 3A, Table 1). The relative level of protein expressed by PBMC was also heavily compromised (ELISA shown for TNF- $\alpha$, IL-8, IL-6 in Figure $3 \mathrm{~B}$ ). These data were consistent with previous reports of low levels of cytokines detected in the TCS of LPS-stimulated PBMC from this patient and other individuals with mutations in the IRAK4 gene [12-18] as well as diminished, but not absent levels of TNF- $\alpha$ and IL-6 in the serum of IRAK4-kinase dead (KD) knockin mice following in vivo administration of LPS [37]. These data (Figure 2, Figure 3, Table 1) illustrated that gene transcription and protein secretion of key pro-inflammatory mediators, while highly variable, was not completely abolished in IRAK4-deficient monocytes exposed to LPS.

\section{Identification of LPS-responsive, IRAK4-independent immunity genes}

While LPS-induced expression of the majority of $\mathrm{NF} \kappa \mathrm{B}$ regulated genes was lowered in IRAK4-deficient monocytes, the TLR-to-NF $\kappa \mathrm{B}$ pathway map (shown in Figure 2) revealed a subset of genes that were expressed at similar (white nodes) or higher (red nodes) levels in
IRAK4-deficient and control cells. It was discovered that approximately $20 \%$ of LPS-responsive genes were expressed in IRAK4-deficient monocytes in a similar manner to that observed in control cells. A subset of LPS-responsive genes associated with host defence that were induced or suppressed to a similar extent $(<1.2$ fold difference) in control and IRAK4-deficient monocytes are listed in Table S1, Additional file 1 (microarray data). Genes of this nature encoded a diverse range of proteins involved in immunity including, but not restricted to, chemokines ( $M D C / C C L 22)$, antibacterial agents (DEFB1), transcription factors (FOS, JUN, RELB), cytokine receptors (IL13RA1) and mRNA-destabilizing agents (ZFP36L2). The uncompromised expression of these genes in IRAK4-deficient cells was confirmed by qPCR (Table 1).

The relatively normal expression of the chemoattractant $M D C / C C L 22$ and the chemotactic host defence (antimicrobial) peptide defensin- $\beta-1$ (DEFB1) in IRAK4deficient monocytes (Figure 4, Table 1 ) contrasted the compromised expression of the chemokines $I L-8$ (neutrophil chemoattractant), Gro- $\alpha / C X C L 1$ (neutrophil chemoattractant), MCP-2/CCL8 (monocyte, lymphocyte, basophil, eosinophil chemoattractant) and $M I P-3 \alpha /$ CCL2O (lymphocyte chemoattractant) (Table 1). The expression of $M D C / C C L 22$ was found to be restricted to $\mathrm{CD} 14^{+}$PBMC (monocytes) and expression in IRAK4deficient monocytes was equivalent to or greater than expression in control monocytes (Figure 4B). ELISA was employed to demonstrate that LPS $(24 \mathrm{hr})$ induced the secretion of 3 -fold more MDC $(3.3 \pm 0.6)$ by the patient's PBMC compared to PBMC from adult or agematched children (Figure 4C). Other CC family members including MPIF/CCL23 and CCL28 (chemotactic for monocytes, $\mathrm{CD}^{+}$and $\mathrm{CD}{ }^{+} \mathrm{T}$ cells) and the chemokine receptor $C X C R 3$ were also expressed at normal levels in IRAK4-deficient cells (ArrayExpress E-FPMI-7). Given that monocytes, dendritic cells, NK cells, and activated $\mathrm{T}$ cells are all chemoattracted by MDC/CCL22, the heightened expression of this chemokine alone has the potential to recruit essential immune cells and thus substantially compensate for the collective absence of chemokines Gro- $\alpha$ /CXCL1, MCP-2/CCL8, MIP-3 $\alpha$ / CCL20 and IL-8.

\section{Gene expression in IRAK4-deficient monocytes was subject to transcriptional and translational regulation} Induced genes in LPS-stimulated, IRAK4-deficient monocytes were likely the result of signal transduction via the MyD88/IRAK4-independent, TRIF/TRAMdependent arm of the TLR4 pathway. Clearly however, LPS-induced activation of the MyD88/IRAK4-independent pathway did not completely compensate for a defect in the MyD88-dependent pathway, neither in the 

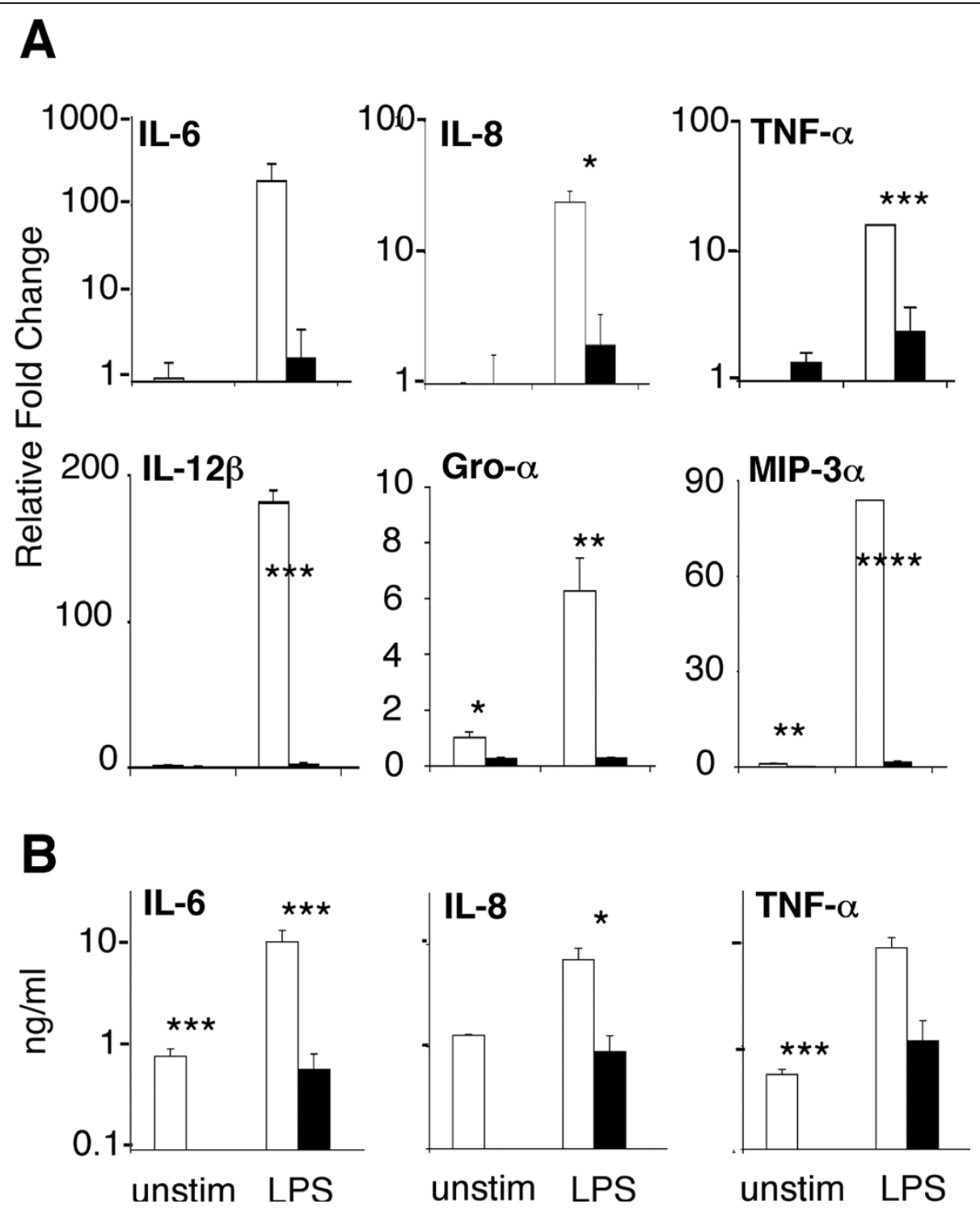

Figure 3 Expression of inflammatory cytokines and chemokines in IRAK4-deficient monocytes. A Expression of IL-6, IL-8, IL-12 $\beta$, TNF- $\alpha$, Gro- $\alpha / C X C L 1$ and MIP-3 $\alpha / C C L 20$ in the healthy control pooled monocytes (white bars) and in both biological replicates of the patient's monocytes (black bars) were evaluated, in duplicate, by qPCR following a $4 \mathrm{hr}$ incubation in the absence or presence of LPS (X-axis). B IL-6, IL-8 and TNF- $\alpha$ were also measured in the tissue culture supernatant of stimulated PBMC by multiplex cytokine bead immunoassays. The Y-axis represents fold change (log scale) in gene expression relative to unstimulated control monocytes (qPCR) or $\mathrm{pg} / \mathrm{ml}$ of protein determined by the cytokine assay. Differences in expression or protein secretion were determined to be statistically significant by Student's two tailed T-test with a value of $\mathrm{p}<0.15\left(^{(*)}, \mathrm{p}<0.1\left(^{* *}\right), \mathrm{p}<0.05\left(^{* *}\right)\right.$ and $\left.\mathrm{p}<0.003{ }^{(* * *}\right)$.

number of expressed genes nor magnitude of their expression.

Kinetic models have estimated that MyD88/IRAK4independent activation of NF $\kappa \mathrm{B}$ via TRIF/TRAM lags the MyD88-dependent pathway by approximately 30 min [38]. We and others previously demonstrated that cells from the IRAK4-deficient patient $[13,14]$ and MyD88-deficient mice [39] do indeed activate NF $\kappa \mathrm{B}$ shortly after exposure to LPS. The depletion of cytoplasmic pools of $\mathrm{NF} \kappa \mathrm{B}$ as a consequence of nuclear translocation stimulates new transcription of $\mathrm{NF} \kappa \mathrm{B}$ subunits in order to replenish cytoplasmic supplies. This phenomenon was observed here (Figure 5A, Table 1) for LPS-activated control monocytes that induced the compensatory expression of all five $\mathrm{NF} \kappa \mathrm{B}$ subunits: $N F \kappa B 1 /$ p50, NF $\kappa B 2 / p 52$, RelA/p65, RelB and $c$-Rel. The compensatory expression of all subunits except RelB was however diminished in IRAK4-deficient cells. The expression of $N F \kappa B 1 / p 50$ and $c-R e l$ was significantly (p $<0.05)$ more impaired after LPS activation than two 
Table 1 Gene expression by qPCR in resting or LPS-activated IRAK4-deficient monocytes relative to gene expression in unstimulated control cells

\begin{tabular}{|c|c|c|c|c|c|}
\hline Gene Name & Monocytes & \multicolumn{2}{|c|}{ Resting } & \multicolumn{2}{|c|}{ LPS } \\
\hline \multirow{2}{*}{ DEFB1 } & Control & ${ }^{\mathrm{a}} 1.1 \pm 0.6$ & \multirow{2}{*}{ up } & $12.6 \pm .0$ & \multirow{2}{*}{$=$} \\
\hline & IRAK4 Q293X & $1.9 \pm 0.9$ & & $9.6 \pm 0.9$ & \\
\hline \multirow{2}{*}{ Fos } & Control & $1.5 \pm 0.1$ & \multirow{2}{*}{$=$} & $0.3 \pm 0.0$ & \multirow{2}{*}{$=$} \\
\hline & IRAK4 Q293X & $1.3 \pm 0.0$ & & $0.3 \pm 0.1$ & \\
\hline \multirow{2}{*}{ Gro-a (CXCL1) } & Control & $1.0 \pm 0.2$ & \multirow{2}{*}{$d n$} & $6.3 \pm 1.2$ & \multirow{2}{*}{$d n$} \\
\hline & IRAK4 Q293X & $0.3 \pm 0.0$ & & $0.3 \pm 0.0$ & \\
\hline \multirow{2}{*}{ IL-6 } & Control & $1.1 \pm 0.6$ & \multirow{2}{*}{$d n$} & $185.4 \pm 110.0$ & \multirow{2}{*}{$d n$} \\
\hline & IRAK4 Q293X & $0.4 \pm 0.5$ & & $1.8 \pm 2.1$ & \\
\hline \multirow{2}{*}{ IL-8 } & Control & $1.0 \pm 0.0$ & \multirow{2}{*}{$=$} & $24.1 \pm 5.5$ & \multirow{2}{*}{$d n$} \\
\hline & IRAK4 Q293X & $0.9 \pm 0.8$ & & $2.0 \pm 1.4$ & \\
\hline \multirow{2}{*}{$\mathrm{IL}-12 \beta$} & Control & $1.0 \pm 0.4$ & \multirow{2}{*}{$d n$} & $181.7 \pm 8.0$ & \multirow{2}{*}{$d n$} \\
\hline & IRAK4 Q293X & $0.2 \pm 0.1$ & & $1.9 \pm 0.8$ & \\
\hline \multirow{2}{*}{ IL-13RA1 } & Control & $1.0 \pm 0.1$ & \multirow{2}{*}{$=$} & $0.3 \pm 0.0$ & \multirow{2}{*}{ up } \\
\hline & IRAK4 Q293X & $1.1 \pm 0.3$ & & $1.9 \pm 0.1$ & \\
\hline \multirow{2}{*}{$\mathrm{IFN}-\gamma$} & Control & $1.0 \pm 0.1$ & $d n$ & $11.0 \pm 0.3$ & $d n$ \\
\hline & IRAK4 Q293X & $0.4 \pm 0.1$ & an & $0.8 \pm 0.3$ & Uin \\
\hline IRE1 & Control & $1.0 \pm 0.1$ & $d n$ & $6.7 \pm 0.1$ & $d n$ \\
\hline Inז? & IRAK4 Q293X & $0.6 \pm 0.1$ & an & $3.1 \pm 0.2$ & an \\
\hline$k B Z$ & Control & $1.1 \pm 0.5$ & $d n$ & $1.3 \pm 0.3$ & $d n$ \\
\hline IKDC & IRAK4 Q293X & $0.4 \pm 0.2$ & an & $0.5 \pm 0.1$ & Uin \\
\hline tun & Control & $1.0 \pm 0.0$ & - & $0.9 \pm 0.2$ & \\
\hline Jun & IRAK4 Q293X & $0.9 \pm 0.3$ & $=$ & $1.7 \pm 0.4$ & up \\
\hline$M C D=(C C L P)$ & Control & $1.0 \pm 0.0$ & $d n$ & $9.4 \pm 0.0$ & $d n$ \\
\hline MICP-L (CCLO) & IRAK4 Q293X & $0.1 \pm 0.0$ & $a n$ & $1.8 \pm 0.2$ & an \\
\hline 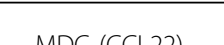 & Control & $1.1 \pm 0.5$ & $d n$ & $4.1 \pm 1.2$ & un \\
\hline MIUL (ICCLZL) & IRAK4 Q293X & $0.6 \pm 0.2$ & $a n$ & $6.4 \pm 1.8$ & up \\
\hline 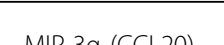 & Control & $1.0 \pm 0.2$ & $d n$ & $83.9 \pm 0.0$ & $d n$ \\
\hline MIIF-Ju (CLLZU) & IRAK4 Q293X & $0.1 \pm 0.0$ & an & $1.4 \pm 0.5$ & an \\
\hline$N E_{K R 1}(n 105 / n 50)$ & Control & $1.0 \pm 0.1$ & $d n$ & $6.8 \pm 0.1$ & $d n$ \\
\hline TNFKDI (PIUS/PSO) & IRAK4 Q293X & $0.3 \pm 0.1$ & $a n$ & $2.3 \pm 0.7$ & $a n$ \\
\hline$N E_{K} B 2(n)(n 0 / n 5)$ & Control & $1.0 \pm 0.0$ & $d n$ & $4.5 \pm 0.7$ & $d n$ \\
\hline TNFEBL (PIOU/PSL) & IRAK4 Q293X & $0.7 \pm 0.0$ & $a n$ & $1.9 \pm 0.3$ & an \\
\hline$N E_{\curlyvee} B \sim B \rho l$ & Control & $1.0 \pm 0.1$ & $d n$ & $3.8 \pm 0.1$ & $d n$ \\
\hline INTKD CREI & IRAK4 Q293X & $0.7 \pm 0.0$ & an & $1.0 \pm 0.0$ & an \\
\hline$N F_{k} R$ RelA $(n 65)$ & Control & $1.0 \pm 0.0$ & - & $3.3 \pm 0.2$ & $d n$ \\
\hline TVIKD REIA (POJ) & IRAK4 Q293X & $1.2 \pm 0.0$ & $=$ & $2.3 \pm 0.4$ & Un \\
\hline AEYR ROlD & Control & $1.0 \pm 0.2$ & - & $1.9 \pm 0.4$ & - \\
\hline TVI KD MEID & IRAK4 Q293X & $0.8 \pm 0.0$ & - & $1.7 \pm 0.3$ & - \\
\hline$S \cap C_{1}$ & Control & $1.2 \pm 0.8$ & $d n$ & $21.2 \pm 4.7$ & $d n$ \\
\hline $50 \mathrm{~s}$ & IRAK4 Q293X & $0.1 \pm 0.1$ & an & $1.6 \pm 0.5$ & an \\
\hline TNEE- & Control & $1.0 \pm 0.1$ & - & $11.3 \pm 4.0$ & $d n$ \\
\hline$T N r-\mathrm{U}$ & IRAK4 Q293X & $0.9 \pm 0.6$ & $=$ & $2.4 \pm 0.7$ & an \\
\hline 7FP 3612 & Control & $1.0 \pm 0.1$ & un & $0.8 \pm 0.0$ & un \\
\hline LTPJOLL & IRAK4 Q293X & $2.1 \pm 0.5$ & up & $2.1 \pm 0.2$ & up \\
\hline
\end{tabular}

a fold changes normalized to endogenous GAPDH in patient or control cells then expressed relative to that in the pool of unstimulated control monocytes (fold change $=1.0) \pm$ the standard deviation of 2 biological and 2 technical replicates. 

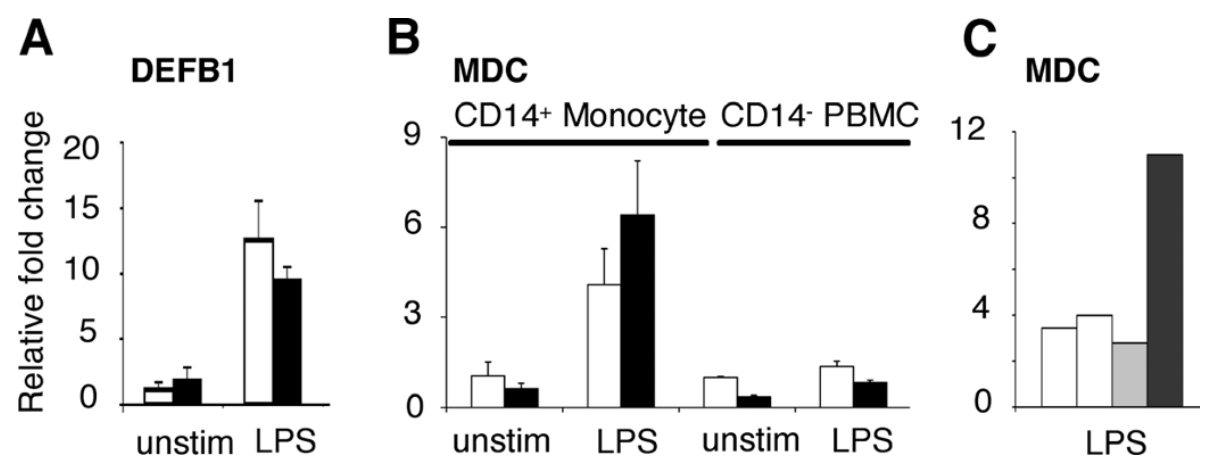

Figure 4 Strong expression of particular chemokines in IRAK4-deficient monocytes. The relative expression (Y-axis) of (A) DEFB1 and (B) MDC/CCL22 in IRAK4-deficient monocytes (black bars), controls (white bars) and for B) CD14- PBMC. Expression was measured in two independent experiments by real-time PCR following $4 \mathrm{hr}$ incubation in the absence or presence of LPS (X-axis). C MDC/CCL22 in the tissue culture supernatant was measured by ELISA in IRAK4-deficient (black bars), adult (white bars) or age-matched (grey bars) PBMC. The result is representative of 2 independent experiments and the $y$-axis represents the relative fold change in protein after stimulation for $24 \mathrm{hr}$ with LPS.

other subunits $(N F \kappa B 2 / p 52$ and $\operatorname{RelA} / p 65)$. Likewise, $I \kappa B \zeta$, a LPS-inducible regulator of $\mathrm{NF} \kappa \mathrm{B}$ that is required for IL-6 transcription [40] was expressed at sub par levels in IRAK4-deficient monocytes (Figure 5A, Table $1)$, which correlated with the compromised expression of IL-6 (Figure 3, Table 1). These data offer evidence that an initial wave of normal $\mathrm{NF} \kappa \mathrm{B}$ activation and gene transcription in IRAK4-deficient cells (via the TRIF/ TRAM pathway) $[13,14]$ would be prematurely truncated due to a substantial deficit in the ability of $\mathrm{NF} \kappa \mathrm{B}$ to induce its own compensatory transcription in response to LPS.

The expression of cytokines, chemokines and transcription factors is also heavily dependent on the stability of transcribed mRNA. AU-rich elements (ARE) are found near the 3' untranslated region (UTR) of these mRNAs and target the message for degradation. The zinc finger protein ZFP36L2, a relative of the prototypic Zinc-finger protein tristetraprolin/TTP, targets the ARE region of TNF- $\alpha$ mRNA, destabilizes the sequence and prevents secretion of TNF- $\alpha$ [41]. The expression of ZFP36L2 was elevated greater than 2fold in IRAK4-deficient monocytes compared to control monocytes (Figure 5B, Table 1), a result consistent with the compromised expression of TNF- $\alpha$ mRNA and protein (Figure 3 ). Another negative regulator of TNF- $\alpha$, IL-13RA1, was upregulated more than 6-fold in LPS-stimulated IRAK4-deficient monocytes (Figure 5B, Table 1). IL-13RA1 mediates translational repression of TNF- $\alpha$ mRNA in LPS-stimulated monocytes and is required for IL-13-mediated protection of mice from lethal endotoxemia [42]. Other mRNA (de)stabilization agents may be direct or indirect substrates of IRAK4, for example, the MAPKs that also act on AREbinding proteins such as TTP were severely impaired in IRAK4-KD BMDM [37].
These results suggest that the expression of $\mathrm{NF} \kappa \mathrm{B}$ regulated genes in IRAK4-deficient cells results from the combined contribution of transcriptional regulation of the gene itself as well as that of other genes that encode elements that influence transcriptional longevity (e.g., $\mathrm{NF} \kappa \mathrm{B})$ and mRNA stability (e.g., ZFP36L2, IL-13RA1). These data offer an explanation for the variable expression, rather than abolishment, of mRNA/protein of various cytokines and chemokines in IRAK4-deficient cells. Furthermore, these data demonstrated that the observed gene expression is regulated and the reciprocal relationships between certain genes (e.g., over-expression of ZFP36L2 \& IL13RA1 with repression of TNF- $\alpha$ ) is preserved, albeit in an unbalanced state compared to IRAK4-competent cells. These data indicate that an initial, but perhaps not subsequent waves of inflammatory mediators are produced in the absence of IRAK4, a result that is in line with a previous suggestion that IRAK4 may only become important in the face of a sustained bacterial challenge [37].

\section{Discussion}

Individuals with defects in key immunity genes, while rare, represent valuable models for understanding the immune system and disease pathogenesis in humans. Sub-optimal expression of particular TLR-responsive genes has become an accepted hallmark of a primary immunodeficiency and a predisposition to infection. In contrast to previous studies that evaluated a selected subset of immunity genes, this study employed microarray technology to evaluate the impact of an IRAK4-deficiency on $21 \mathrm{~K}$ human genes. The absence of IRAK4 compromised the appropriate expression of 567 LPSresponsive genes in human monocytes, including a broad array of genes (pro-inflammatory interleukins, $\mathrm{CXC}$ and $\mathrm{CC}$ chemokines, and $\mathrm{NF} \kappa \mathrm{B}$ subunits) 


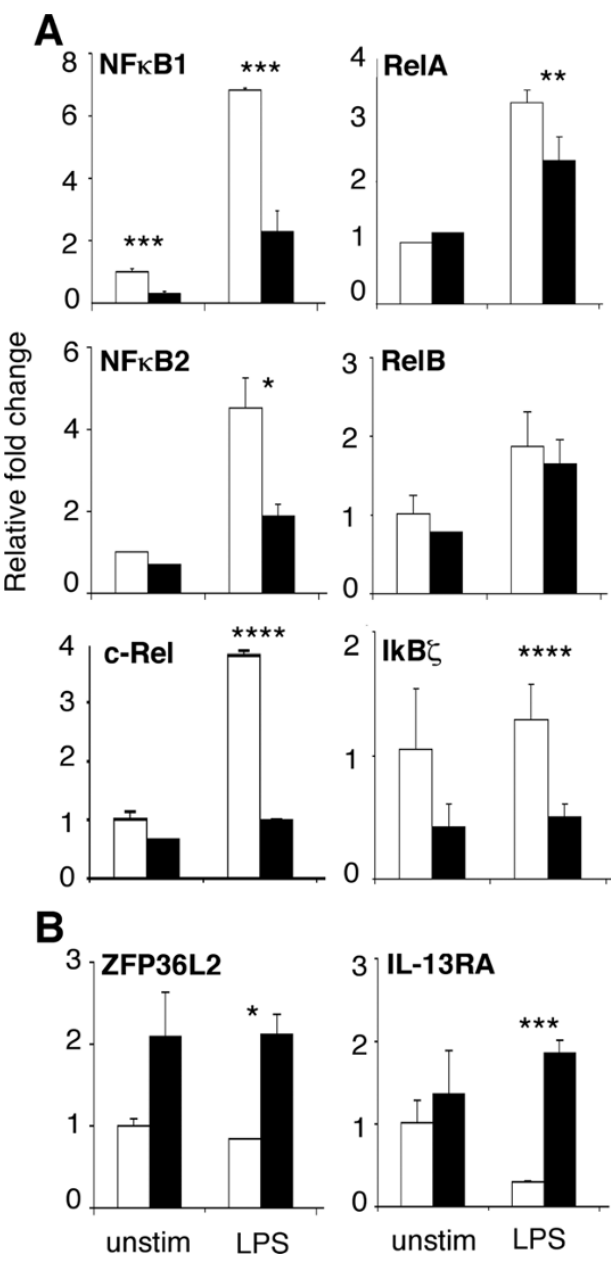

Figure 5 Differential regulation of elements that regulate gene transcription and translation in IRAK4-deficient monocytes. The relative expression (Y-axis) of (A) NF $\kappa B$ subunits NF $\kappa B 1$ (p105/50), $\mathrm{NF} \kappa \mathrm{B} 2$ (p100/52), RelA (p65), RelB \& c-Rel, NF $\kappa$ B regulator $\mid \kappa B \zeta$, and (B) translational suppressors IL-13RA \& ZFP36L2 in IRAK4-deficient monocytes (black bars) and controls (white bars) was measured by real-time PCR following $4 \mathrm{hr}$ incubation in the absence or presence of LPS (X-axis). Results show gene expression relative to unstimulated control monocytes and are representative of 3 independent experiments. Differences in expression were determined to be statistically significant by Student's two tailed Ttest with a value of $\mathrm{p}<0.15\left(^{(*)}, \mathrm{p}<0.1\left(^{* *}\right), \mathrm{p}<0.05\left(^{(* *)}\right.\right.$ or $\mathrm{p}<$ $\left.0.01{ }^{* * * *}\right)$.

implicated in inflammation and immunity. In accordance with previous analyses on a much smaller subset of genes and proteins, the global disruption of gene expression in IRAK4-deficient cells conclusively demonstrated that IRAK4 plays a pivotal role in transmission of signals along the TLR4 pathway that culminate in robust pro-inflammatory gene transcription. Based on the current belief that robust TLR4-responsiveness is a requirement for immunity, these data would also have led us to predict that IRAK4-deficient children would be highly susceptible to Gram negative infections.

The clinical data, however, indicate that invasive infection by Gram negative bacteria are at most a rare occurrence in IRAK4-deficient children despite severely compromised responses of IRAK4-deficient cells to LPS. To confirm this phenotype in a controlled situation, we utilized IRAK4-deficient mice to quickly ascertain their ability to survive infection by a Gram negative bacterium in vivo. These mice, like IRAK4-deficient children, are susceptible to infections by Gram positive bacteria and fail to produce inflammatory cytokines in response to LPS [19-24]. We now demonstrate that IRAK4 knockout mice and wildtype mice have a similar resistance to challenge with Gram negative bacteria, thereby providing strong evidence that effective immunity is maintained and may account for the relatively few cases of Gram negative infections in mice and children with an IRAK4-deficiency.

These data are consistent with the hypothesis that a robust transcriptional response to LPS is not essential as long as key aspects of the immune response are maintained; such a hypothesis must be qualified given that the complete absence of such responses in MyD88 knockout mice does influence susceptibility to Gram negative infections. Such subtle changes in the elements of the immune system, including for e.g., polymorphisms in certain genes are becoming increasingly recognized as sufficient to alter immunity [43]. For example only 250 genes are included within the major locus of variability between $S$. pneumoniae-sensitive and -resistant strains of mice [44]. During the course of this study, we also evaluated the transcriptional responsiveness of IRAK4-deficient cells to peptidoglycan (PGN). This component of the cell wall of Gram positive bacteria stimulates several innate immunity receptors, including TLR2. Despite a predisposition of IRAK4-deficient children to Gram positive infections, we observed relatively normal transcriptional responses of IRAK4deficient monocytes to PGN (data included in ArrayExpress E-FPMI-7). These data also suggested to us that immunity is quite complex and cannot necessarily be inferred from even a global assessment of agonistinduced transcriptional responses.

If one accepts at least a portion of the prevailing dogma and assumes that essential elements of Gram negative immunity are contained within the transcriptional response to LPS, it is possible to speculate, based on the data provided here, that these key elements either (1) include classical pro-inflammatory cytokines and chemokines that adequately perform immunological function(s) at reduced concentrations (e.g., TNF- $\alpha$, IL-6) or (2) are contained within the subset of genes that were expressed to similar levels in IRAK4-deficient and 
control monocytes (e.g., MDC/CCL22, DEFB1). Consistent with these concepts, it was recently demonstrated that innate defence regulator peptides, which suppress pro-inflammatory cytokines but substantially maintain chemokine responses, are able to protect against Salmonella infections [30]. The functional redundancy of chemokines is an example of how the expression of just a few genes might be sufficient to support critical immunological functions such as cellular recruitment, despite the severe impairment of the expression of other family members. As demonstrated here, the expression of IL-8/ CXCL8, Gro- $\alpha / C X C L 1$, MCP-2/CCL8 and MIP-3 $\alpha /$ CCL20 was compromised in LPS-stimulated IRAK4deficient monocytes (Figure 3, Table 1), suggesting a diminished recruitment of neutrophils, monocytes, lymphocytes, basophils and eosinophils to sites of infection. However, the chemokines MDC/CCL22, MPIF/CCL23, CCL28 and DEFB1 were robustly expressed in the absence of IRAK4 (Figure 5 and ArrayExpress), implying that monocytes, dendritic cells, natural killer cells, memory $\mathrm{T}$ cells, and activated $\mathrm{CD}_{4}^{+}$and $\mathrm{CD}^{+} \mathrm{T}$ cells, particularly $\mathrm{CD} 4^{+} \mathrm{T}$-helper-2 (Th2) cells could still be mobilized in response to LPS. The enhanced recruitment of Th2 cells that express IL- 4 and IL- 13 would be consistent with the elevated expression of IL-13RA1 (Figure 5), as well as reports of relatively normal antibody responses to vaccination in some children with IRAK4-deficiency $[15,16]$. Similar to our findings in human IRAK4-deficient monocytes, a number of chemokines were expressed at similar levels in murine BMDM from wildtype and IRAK4-kinase-defective knock-in mice, such as CXCL2, CXCL10, CXCL11, CCL2 and CCL4 [Clusters I and III in [37]]. We propose that the observed differential expression of chemokines is sufficient to appropriately change the cellular milieu at the site of infection and favourably impact on the outcome to infection [45]. Without supporting in vivo data however, these results are at best speculative. It should however be noted that infections in patients with IRAK4-deficiency are pyogenic (pus-forming) and can lead to mild fever and inflammation at late stages of infection [12]. This in vivo evidence implies that certain inflammatory mediators must have been produced and that cells are actively recruited to the site of infection in IRAK4-deficient individuals. Furthermore, TNF $\alpha$ and IL-6 were detected, albeit at low levels in the serum of IRAK4-KD mice following administration of LPS [37].

Other potential candidate elements that might mediate defence include the $>60$ upregulated genes and 20 down regulated genes listed in Table S1, Additional file 1 (genes with similar or exaggerated expression in IRAK4deficient cells compared to controls). Some of these genes in the ADAM, ICAM, integrin and NF $\kappa$ B families were also regulated in a similar fashion in IRAK4-KD and control BMDM stimulated with LPS [37]. Although $\mathrm{GO}$ analysis did not predict a disturbance in any major biological process in resting (unstimulated) IRAK4-deficient monocytes, we identified more than 50 LPSresponsive genes that were expressed in resting IRAK4deficient cells not exposed to LPS (Table S2, Additional file 2). Notable genes include cytokines \& chemokines (IL1F9, MIP-2 $\alpha / C X C L 2)$, transcription factors \& transcriptional regulators (c-REL, NFKB1A, IBRDC2, $U B E 2 N, U S P 9 Y, B A C H 1)$, cell adhesion molecules (CD44), signalling molecules (MAPK6, PRKAG2, $C A L M 3)$ and other pro-inflammatory mediators (ALOX5, HIF3 $\alpha$, HLA-DMA, LILRA3). It is tempting speculate that these differentially expressed genes in unstimulated, IRAK4-deficient cells may also contribute to successful host defences.

LPS-induced gene expression in IRAK4-deficient cells is subject to regulation by both transcriptional and translational mechanisms and is the product of signal transduction via either (1) the MyD88-independent, TRIF/TRAM pathway or (2) MyD88-dependent, IRAK4independent pathways. Björkbacka and colleagues have demonstrated that only $20 \%$ of more than 1000 LPSresponsive genes in macrophages are in fact dependent on MyD88 [46]. We however favour the hypothesis that a subset of MyD88-dependent, IRAK4-independent genes are imperative for immunity since MyD88-deficient mice are susceptible to a broader range of pathogens, including Gram negative bacteria, than are caused by IRAK4-deficiency in mice and humans. MyD88dependent pathways that transduce signals independent of IRAK4 utilize signalling molecules such as PI3K, Btk, Tlp-2, and NIK and activate MAPKs and NF $\kappa$ B. Regardless, it can be concluded that pathways other than the classic MyD88-dependent pathway (via sequential activation of IRAK4, IRAK1, TRAF6, IKK and NF $\kappa$ B) have essential and under-appreciated roles in defence against Gram negative bacteria.

\section{Conclusions}

In this study, we demonstrated that the expression of the vast majority of LPS-induced inflammatory and immunity genes were compromised (compared to the expression levels in control cells) in monocytes from a child with IRAK4 deficiency. We conclude that while IRAK4 is imperative for a comprehensive transcriptional response to LPS, neither IRAK4, nor this classical, robust transcriptional response is required for effective host defences against Gram negative infection. Instead, the data implies that sufficient defence could lie within a small repertoire of LPS-responsive, IRAK4-independent genes. A subset of transcribed genes amidst a severely impaired response to LPS was also observed by Koziczak-Holbro et al in murine BMDM from IRAK4- 
kinase-defective knockin mice [37]. These observations are consistent with the concept that it may be possible to generate an effective immune response without a robust inflammatory response [47] and such properties may even make IRAK4 an attractive drug target for treating inflammation without compromising effective immune defences [48].

Additional file 1: Table S1. Selection of LPS-responsive immunity genes that were expressed to similar or exaggerated (italics) levels in IRAK4deficient monocytes compared to controls as assayed by microarray analysis

Click here for file

[http://www.biomedcentral.com/content/supplementary/1479-5876-8-6S1.PDF ]

Additional file 2: Table S2. Selection of LPS-responsive genes expressed in unstimulated IRAK4-deficient monocytes

Click here for file

[http://www.biomedcentral.com/content/supplementary/1479-5876-8-6S2.PDF ]

\section{Acknowledgements}

We gratefully acknowledge the support of Genome Prairie and Genome BC for the Pathogenomics of Innate Immunity research program and the Canadian Institutes for Health Research (CIHR). KLB received support from a postdoctoral fellowship from the CIHR-UBC Strategic Training Program for Translational Research in Infectious Diseases (TRID) and the European Community's Seventh Framework Programme (FP7/2007-2013) under grant agreement number 221094. DJD is supported by the Wellcome Trust. JLG received a postdoctoral fellowship from the Michael Smith Foundation for Health Research. DPS is supported by operating grants from the CIHR and the Canadian Bacterial Diseases Network. B.B.F. is a CIHR Distinguished Investigator, a Howard Hughes Medical Institute International Research Scholar, and the University of British Columbia Peter Wall Distinguished Professor. REWH is the recipient of a Canada Research Chair Award. The authors would like to thank Rebecca Ma, Yuexin Li, Dawn Bowdish, ShuYu Fan, Jessica Li, George Song-Zhao, and Aaron Hirschfeld for technical support, and the patient and his family for their cooperation.

\section{Author details}

'Centre for Microbial Diseases and Immunity Research, Department of Microbiology and Immunology, University of British Columbia, Vancouver, British Columbia, V6T 1Z3, Canada. ${ }^{2}$ Child and Family Research Institute, University of British Columbia, 950 West 28th Avenue, Vancouver, British Columbia, V5Z 4H4, Canada. ${ }^{3}$ Current address: MRC/University of Edinburgh Centre for Inflammation Research, Queen's Medical Research Institute W2 03, 47 Little France Crescent, Edinburgh EH16 4T, UK. ${ }^{4}$ Current address: Department of Rheumatology and Inflammation Research, University of Gothenburg, Guldhedsgatan 10, S-413 46 Gothenburg, Sweden.

\section{Authors' contributions}

$\mathrm{KLB}$ carried out the in vitro cell culture, RNA isolation, $\mathrm{QPCR}$, ELISA and manuscript preparation. RF carried out the microarray analysis. WK carried out the animal studies. JLG performed bioinformatics analyses. PH added valuable insight into data analysis, manuscript content and presentation. DJD, ST and BBF provided advice on the conception and design of the clinical and animal experiments. DPS and REWH were imperative to the conception, design and implementation of the experiments and preparation of the manuscript. All authors read and approved the final manuscript.

\section{Competing interests}

The authors declare that they have no competing interests.

Received: 27 July 2009

Accepted: 27 January 2010 Published: 27 January 2010

\section{References}

1. Akira S, Uematsu S, Takeuchi O: Pathogen Recognition and Innate Immunity. Cell 2005, 124:783-801

2. Martino F, Tschoop J: NLRs join TLRs as innate sensors of pathogens. Trends Immunol 2005, 26:449-454

3. Akira S, Takeda K: Toll-like receptor signalling. Nat Rev Immunol 2004 4:499-511.

4. Dunne $A, O^{\prime}$ Neill LA: Adaptor usage and Toll-like receptor signalling specificity. FEBS Lett 2005, 579:3330-3335.

5. Kim T, Kim YJ: Overview of innate immunity in Drosophila. J Biochem Mol Biol 2005, 38:121-127.

6. Akira S: Toll-like receptors: lessons from knockout mice. Biochem Soc Trans 2000, 28:551-556.

7. Takeuchi O, Hoshino K, Akira S: Cutting edge: TLR2-deficient and MyD88deficient mice are highly susceptible to Staphylococcus aureus infection. J Immunol 2000, 165:5392-5396.

8. Skerrett SJ, Liggitt HD, Hajjar AM, Wilson CB: Cutting edge: myeloid differentiation factor 88 is essential for pulmonary host defence against Pseudomonas aeruginosa but not Staphylococcus aureus. J Immunol 2004, 172:3377-3381.

9. Fremond CM, Yeremeev V, Nicolle DM, Jacobs M, Quesniaux VF, Ryffel B: Fatal Mycobacterium tuberculosi s infection despite adaptive immune response in the absence of MyD88. J Clin Invest 2004, 114:1790-1799.

10. Feng CG, Scanga CA, Collazo-Custodio CM, Cheever AW, Hieny S, Caspar P, Sher A: Mice lacking myeloid differentiation factor 88 display profound defects in host resistance and immune responses to Mycobacterium avium infection not exhibited by Toll-like receptor 2 (TLR2)- and TLR4deficient animals. J Immunol 2003, 171:4758-4764.

11. Seki E, Tsutsui H, Tsuji NM, Hayashi N, Adachi K, Nakano H, FutatsugiYumikura S, Takeuchi O, Hoshino K, Akira S, Fujimoto J, Nakanishi K: Critical roles of myeloid differentiation factor 88-dependent proinflammatory cytokine release in early phase clearance of Listeria monocytogenes in mice. J Immunol 2002, 169:3863-3868.

12. Ku CL, Yang K, Bustamante Puel A, von Bernuth A, Santos OF, Lawrence T, Chang HH, Al-Mousa H, Picard C: Inherited disorders of human Toll-like receptor signalling: immunological implications. Immunol Rev 2005, 203:10-20.

13. Currie AJ, Davidson DJ, Reid GS, Bharya S, MacDonald KL, Devon RS, Speert DP: Primary immunodeficiency to pneumococcal infection due to a defect in Toll-like receptor signalling. J Pediatr 2004, 144:512-518.

14. Davidson DJ, Currie AJ, Bowdish DME, Brown KL, Rosenberger CM, Ma RC, Bylund J, Campsall PA, Puel A, Picard C, Casanova JL, Turvey SE, Devon RE, Hancock REW, Speert DP: IRAK-4 mutation (Q293X): rapid detection and characterization of defective post-transcriptional TLR/IL1R responses in human myeloid and non-myeloid cells. J Immunol 2006, 177:8202-8211.

15. Picard C, Puel A, Bonnet M, Ku CL, Bustamante J, Yang K, Soudais C, Dupuis S, Feinberg J, Fieschi C, Elbim C, Hitchcock R, Lammas D, Davies G, Al-Ghonaium A, Al-Rayes H, Al-Jumaah A, Al-Hajjar S, Al-Mohsen IZ, Frayha HH, Rucker R, Hawn TR, Aderem A, Tufenkji H, Haraguchi S, Day NK, Good RA, Gougerot-Pocidalo MA, Ozinsky A, Casanova JL: Pyogenic bacterial infections in humans with IRAK-4 deficiency. Science 2003, 299:2076-2079.

16. Medvedev AE, Lentschat A, Kuhns DB, Blanco JC, Salkowski C, Zhang S, Arditi M, Gallin Jl, Vogel SN: Distinct mutations in IRAK-4 Confer hyporesponsiveness to lipopolysaccharide and interleukin-1 in a patient with recurrent bacterial infections. J Exp Med 2003, 198:521-531.

17. Chapel H, Puel A, von Bernuth H, Picard C, Casanova JL: Shigella sonnei meningitis due to interleukin-1 receptor-associated kinase-4 deficiency: first association with a primary immune deficiency. Clin Infect Dis 2005, 40:1227-1231.

18. Enders A, Pannicke U, Berner R, Henneke P, Radlinger K, Schwarz K, Ehl S: Two siblings with lethal pneumococcal meningitis in a family with a mutation in Interleukin-1 receptor-associated kinase 4. J Pediatr 2004, 145:698-700

19. Suzuki N, Suzuki S, Duncan GS, Millar DG, Wada T, Mirtsos C, Takada H, Wakeham A, Itie A, Li S, Penninger JM, Wesche H, Ohashi PS, Mak TW, Yeh WC: Severe impairment of interleukin-1 and Toll-like receptor signalling in mice lacking IRAK-4. Nature 2002, 416:750-756.

20. Vosse van de E, van Dissel JT, Ottenhoff TH: Genetic deficiencies of innate immune signalling in human infectious disease. Lancet Infect Dis 2009, 9:688-698 
21. Ku CL, von Bernuth H, Picard C, Zhang SY, Chang HH, Yang K, Chrabieh M Issekutz AC, Cunningham CK, Gallin J, Holland SM, Roifman C, Ehl S, Smart J, Tang M, Barrat FJ, Levy O, McDonald D, Day-Good NK, Miller R, Takada H, Hara T, Al-Hajjar S, Al-Ghonaium A, Speert D, Sanlaville D, Li X, Geissmann F, Vivier E, Maródi L, Garty BZ, Chapel H, Rodriguez-Gallego C, Bossuyt X, Abel L, Puel A, Casanova JL: Selective predisposition to bacterial infections in IRAK-4-deficient children: IRAK-4-dependent TLRs are otherwise redundant in protective immunity. J Exp Med 2007, 204:2407-2422.

22. Suzuki N, Suzuki S, Eriksson U, Hara H, Mirtosis C, Chen NJ, Wada T, Bouchard D, Hwang I, Takeda K, Fujita T, Der S, Penninger JM, Akira S, Saito T, Yeh WC: IL-1R-associated kinase 4 is required for lipopolysaccharide-induced activation of APC. J Immunol 2003, 171:6065-6071.

23. Kawagoe T, Sato S, Jung A, Yamamoto M, Matsui K, Kato H, Uematsu S, Takeuchi O, Akira S: Essential role of IRAK-4 protein and its kinase activity in Toll-like receptor-mediated immune responses but not in TCR signalling. J Exp Med 2007, 204:1013-1024

24. Kim TW, Staschke K, Bulek K, Yao J, Peters K, Oh KH, Vandenburg Y, Xiao H, Qian W, Hamilton T, Min B, Sen G, Gilmour R, Li X: A critical role for IRAK4 kinase activity in Toll-like receptor-mediated innate immunity. J Exp Med 2007, 204:1025-1036.

25. Mookherjee N, Brown KL, Bowdish DME, Doria S, Falsafi R, Hokamp K, Roche RM, Mu R, Doho GH, Pistolic J, Powers JP, Bryan J, Brinkman FS, Hancock RE: Modulation of the Toll-like receptor-mediated inflammatory response by the endogenous human host defence peptide LL-37. J Immunol 2006, 176:2455-2464.

26. Hirschfeld AF, Bettinger JA, Victor RE, Davidson DJ, Currie AJ, Ansermino JM, Scheifele DW, Orange JS, Turvey SE: Prevalence of Toll-like receptor signalling defects in apparently healthy children who developed invasive pneumococcal infection. Clin Immunol 2007, 122:271-8.

27. Brown KL, Maiti A, Johnson P: Role of sulfation in CD44-mediated hyaluronan binding induced by inflammatory mediators in human CD14 + peripheral blood monocytes. J Immunol 2001, 167:5367-5374.

28. Brown KL, Bylund J, MacDonald KL, Song-Zhao GX, Elliott M, Falsafi R, Hancock R, Speert DP: ROS-deficient monocytes have aberrant gene expression that correlates with inflammatory disorders of chronic granulomatous disease. Clin Immunol 2008, 129:90-102.

29. Scott MG, Dullaghan E, Mookherjee N, Glavas N, Waldbrook M, Thompson A, Wang A, Lee K, Doria S, Hamill P, Yu JJ, Li Y, Donini O, Guarna MM, Finlay BB, North JR, Hancock REW: An anti-infective peptide that selectively modulates the innate immune response. Nat Biotechnol 2007, 25:465-472.

30. Hokamp K, Roche FM, Acab M, Rousseau ME, Kuo B, Goode D, Aeschliman D, Bryan J, Babiuk LA, Hancock REW, Brinkman FS: ArrayPipe: a flexible processing pipeline for microarray data. Nucl Acids Res 2004, 32: W457-459.

31. Shannon P, Markiel A, Ozier Q, Baliga NS, Wang JT, Ramage D, Amin N, Schwikowski B, Ideker T: Cytoscape: a software environment for integrated models of biomolecular interaction networks. Genome Res 2003, 13:2498-2504.

32. Zhang B, Schmoyer D, Kirov K, Snoddy J: GOTree Machine (GOTM): a webbased platform for interpreting sets of interesting genes using Gene Ontology hierarchies. BMC Bioinformatics 2004, 5:16-23.

33. Hoiseth SK, Stocker BA: Aromatic-dependent Salmonella typhimurium are non-virulent and effective as live vaccines. Nature 1981, 291:238-239.

34. Faure K, Sawa T, Ajayi T, Fujimoto J, Moriyama K, Shime N, WienerKronish JP: TLR signalling is essential for survival in acute lung injury induced by virulent Pseudomonas aeruginosa secreting type III secretory toxins. Respir Res 2004, 5:1-10.

35. Mahieu T, Park JM, Revets H, Paschel B, Lengeling A, Staelens J, Wullaert A, Vanlaere I, Hochepied T, van Roy F, Karin M, Libert C: The wild-derived inbred mouse strain SPRET_Ei is resistant to LPS and defective in IFN- $\beta$ production. PNAS 2006, 103:2292-2297.

36. Modlin RL, Brightbill HD, Godowski PJ: The Toll of Innate Immunity on Microbial Pathogens. NEJM 1999, 340:1834-1835.

37. Koziczak-Holbro M, Glück A, Tschopp C, Mathison JC, Gram H: IRAK-4 kinase activity-dependent and -independent regulation of lipopolysaccharide-inducible genes. Eur J Immunol 2008, 38:788-96.
38. Covert MW, Leung TH, Gaston JE, Baltimore D: Achieving stability of lipopolysaccharide-induced NF-kappaB activation. Science 2005, 309:1854-1857.

39. Kawai T, Adachi O, Ogawa T, Takeda K, Akira S: Unresponsiveness of MyD88-deficient mice to endotoxin. Immunity 1999, 11:115-122.

40. Yamamoto M, Yamazaki S, Uematsu S, Sato S, Hemmi H, Hoshino K, Kaisho T, Kuwata H, Takeuchi O, Takeshige K, Saitoh T, Yamaoka S, Yamamoto N, Yamamoto S, Muta Tm, Takeda K, Akira S: Regulation of Toll/ IL-1-receptor-mediated gene expression by the inducible nuclear protein IkappaBzeta. Nature 2004, 430:218-222.

41. Carballo E, Lai WS, Blackshear PJ: Feedback inhibition of macrophage tumor necrosis factor-alpha production by tristetraprolin. Science 1998, 281:1001-1005.

42. Muchamuel T, Menon S, Pisacane P, Howard MC, Cockayne DA: IL-13 protects mice from lipopolysaccharide-induced lethal endotoxemia: correlation with down-modulation of TNF-alpha, IFN-gamma, and IL-12 production. J Immunol 1997, 158:2898-2903

43. Pasare C, Medzhitov R: Control of B-cell responses by Toll-like receptors. Nature 2005, 438:364-368.

44. Denny P, Hopes E, Gingles N, Broman KW, McPheat W, Morten J, Alexander J, Andrew PW, Brown SD: A major locus conferring susceptibility to infection by Streptococcus pneumoniae in mice. Mamm Genome 2003, 14:448-453.

45. Esche C, Stellato C, Beck LA: Chemokines: key players in innate and adaptive immunity. J Invest Dermatol 2005, 125:615-628.

46. Björkbacka H, Fitzgerald KA, Huet F, LI X, Gregory JA, Lee MA, Ordija CM, Dowley NE, Golenbock DT, Freeman MW: The induction of macrophage gene expression by LPS predominantly utilizes Myd88-independent signaling cascades. Physiological Genomics 2004, 19:319-330.

47. Brown KL, Cosseau C, Gardy JL, Hancock REW: Complexities of targeting innate immunity to treat infection. Trends Immunol 2007, 28:260-66.

48. Li X: IRAK4 in TLR/L-1R signalling: possible clinical applications. Eur J Immunol 2008, 38:614-618.

doi:10.1186/1479-5876-8-6

Cite this article as: Brown et al:: Robust TLR4-induced gene expression patterns are not an accurate indicator of human immunity. Journal of Translational Medicine 2010 8:6.

\section{Submit your next manuscript to BioMed Central and take full advantage of:}

- Convenient online submission

- Thorough peer review

- No space constraints or color figure charges

- Immediate publication on acceptance

- Inclusion in PubMed, CAS, Scopus and Google Scholar

- Research which is freely available for redistribution

Submit your manuscript at www.biomedcentral.com/submit
C Bïomed Central 